\title{
Efeitos da redução da proteína dietética sobre o desempenho e as características de carcaça de frangos de corte de 1 a 21 dias de idade
}

\section{Carlos Henrique de Figueiredo Vasconcellos ${ }^{1}$, Dalton de Oliveira Fontes ${ }^{1}$, Gerusa da Silva Salles Corrêa ${ }^{2}$, Tatiana Zacché Batista Vidal ${ }^{1}$, Martinho de Almeida e Silva ${ }^{1}$, André Luiz Costa Machado ${ }^{1}$, Isabela Sabino Fernandes ${ }^{1}$, Flávio Medeiros Vieites ${ }^{3}$}

\footnotetext{
1 Universidade Federal de Minas Gerais.

2 Universidade Federal de Mato Grosso - Campus Cuiabá.

${ }^{3}$ Universidade Federal de Mato Grosso - Campus Rondonópolis.
}

RESUMO - O experimento foi conduzido em delineamento inteiramente ao acaso para avaliar os efeitos da redução de proteína (PB) e da suplementação de aminoácidos essenciais sobre o desempenho e as características de carcaça de frangos de corte machos de linhagem comercial na fase de 1 a 21 dias de idade. Foram utilizados 720 frangos distribuídos em 4 tratamentos e seis repetições com 30 aves cada. Os níveis de PB utilizados foram 230, 210, 190 e 170 g/kg. Houve efeito linear decrescente dos níveis de PB sobre a conversão alimentar, o ganho de peso, o peso final e o consumo. Houve aumento linear dos teores de gordura e matéria seca das carcaças com a redução do conteúdo de proteína da dieta.

Palavras-chave: aminoácidos, conversão alimentar, níveis de proteína

\section{Reduction of dietary protein on performance and carcass of broiler chickens from 1 to 21 days of age}

\begin{abstract}
A completely randomized experimental design was carried out to evaluate the crude protein reduction of diets and essential amino acids supplementation effects on performance and body composition of male broiler chickens from one to 21 days of age. A total of seven hundred and twenty broiler chickens were used. Birds were alloted in four treatments and six replicates of thirty birds each. The diets crude protein (CP) levels were 230, 210, 190 and $170 \mathrm{~g} / \mathrm{kg}$. There was decreasing linear effect of the CP levels on feed:gain ratio, weight gain, the final weight and feed intake. Carcass fat and carcass dry matter increased linearly with protein reduction.
\end{abstract}

Key Words: amino acids, feed conversion, protein levels

\section{Introdução}

Os resultados experimentais registrados na literatura são variados e às vezes contraditórios quanto ao desempenho e à composição de carcaça de frangos alimentados com dietas contendo vários níveis de proteína bruta. Sabe-se que as exigências de frangos de corte não são de proteína bruta, mas sim de aminoácidos essenciais e,ou quantidades suficientes de nitrogênio para a síntese de aminoácidos não-essenciais.

Entre os fatores dietéticos que influenciam as exigências de aminoácidos, podem ser incluídos a concentração de energia metabolizável, o desequilíbrio de aminoácidos e o nível de proteína bruta da dieta (Leeson \& Summers, 2001). O balanceamento adequado de aminoácidos e proteína para frangos de corte é fundamental, seja pelo peso da proteína no custo total da formulação seja pelo resultado esperado para os níveis de aminoácidos empregados.

De acordo com Skalan \& Plavnik (2002), rações para frangos de corte devem ser formuladas para fornecer aminoácidos suficientes para a síntese proteica, uma vez que o consumo excessivo de aminoácidos pode resultar em queda na sua eficiência de utilização e aumento da exigência de aminoácidos essenciais. Isso ocorre porque o excesso de proteína é catabolizado na forma de ácido úrico e esse processo tem alto custo energético. Estima-se que, para incorporar um aminoácido na cadeia proteica gastam-se em torno de 4 mols de trifosfato de adenosina (ATP), enquanto, para excretar um aminoácido, são gastos 6 a 18 mols de ATP, dependendo de sua quantidade de nitrogênio. Dessa forma, com aminoácido em excesso, a ave gasta energia para eliminar o excesso de nitrogênio, 
energia que deveria estar sendo utilizada para crescimento e manutenção corporal.

Rostagno et al. (2002) observaram que, com a formulação de dietas com menor conteúdo de proteína usando a proteína ideal, é possível obter desempenho similar ao das aves alimentadas com dietas contendo altos níveis proteicos. Por outro lado, alguns autores têm relatado prejuízo no desempenho e aumento do conteúdo de gordura na carcaça dos animais alimentados com dietas com baixos níveis proteicos, mesmo suprindo as necessidades em aminoácidos limitantes (Bregendahl et al., 2002; Faria Filho et al., 2005). Existem, portanto, resultados contraditórios relacionados à redução proteica em dietas para frangos de corte.

Assim, este trabalho foi realizado com o objetivo de avaliar os efeitos da redução dos níveis de proteína bruta da dieta sobre o desempenho e a composição de carcaça de frangos de corte de 1 a 21 dias de idade.

\section{Material e Métodos}

O experimento foi realizado no Setor de avicultura do Departamento de Zootecnia da Universidade Federal de Minas Gerais, localizado na Fazenda Experimental Prof. Hélio Barbosa no município de Igarapé, Minas Gerais.

As aves foram alojadas em galpão de alvenaria com piso de concreto, dividido em boxes de estrutura metálica (60 boxes idênticos com $3 \mathrm{~m}^{2}$, sendo 30 boxes de cada lado) forrados com cepilho de madeira. Foi utilizado um termômetro de máxima e mínima, colocado no interior do galpão, para registro diário das temperaturas.

Utilizaram-se 720 pintos de corte machos da linhagem comercial Ross de 1 a 21 dias de idade distribuídos em delineamento inteiramente casualisado. Foram utilizados 4 tratamentos e seis repetições, sendo alojadas 30 aves/ boxe $\left(10\right.$ aves $\left./ \mathrm{m}^{2}\right)$. As aves foram vacinadas no incubatório de origem contra a doença de Marek e, aos 12 dias de idade, contra a doença de Gumboro, via água de bebida.

Até os 14 dias de idade, as aves receberam aquecimento artificial por meio de uma lâmpada infravermelha por boxe. Durante os primeiros sete dias de alojamento, foi utilizado um bebedouro tipo copo de pressão para cada 30 aves, juntamente com um bebedouro pendular automático para cada boxe. O bebedouro pendular foi mantido até o período final de criação. De 1 aos 14 dias de idade, foi utilizado um comedouro tubular tipo infantil para cada boxe, que foi trocado pelo comedouro tubular adulto, que permaneceu dos 14 aos 21 dias.

O programa de luz utilizado foi de 24 horas no período de 1 a 14 dias, e de luz natural de 14 a 21 dias de idade. As temperaturas máxima e mínima durante o período experimental variaram entre $28 \pm 3,5{ }^{\circ} \mathrm{C}$ e $15 \pm 3,0{ }^{\circ} \mathrm{C}$, respectivamente.

Foram utilizadas quatro dietas (Tabela 1) com níveis de proteína bruta decrescentes para determinação dos efeitos sobre o desempenho e as características de carcaça das aves. Os níveis utilizados de proteína bruta das dietas foram de 230, 210, 190 e $170 \mathrm{~g} / \mathrm{kg}$. As dietas foram formuladas de forma a atender às exigências nutricionais das aves, descritas por Rostagno et al. (2005); aquelas com menores níveis proteicos foram suplementadas com aminoácidos sintéticos (L-lisina; DL-metionina; L-treonina; L-triptofano; L-isoleucina, L-valina e L-arginina) de forma a atender à relação entre lisina digestível e os demais aminoácidos essenciais. As rações foram suplementadas com casca de soja para manter constante o nível de fibra bruta da dieta e foram fornecidas à vontade durante todo período experimental.

As aves foram pesadas com 1 e 21 dias de idade. $\mathrm{O}$ ganho de peso foi calculado descontando-se o peso inicial dos pintos ao alojamento no primeiro dia. O consumo de ração foi determinado a partir da quantidade de ração oferecida subtraindo-se a sobra no final do período experimental, considerando o número de aves mortas na semana. O cálculo de conversão alimentar foi feito a partir do consumo médio de ração e do ganho médio de peso das aves ao final da fase de criação. O número de aves mortas foi registrado diariamente para determinação da porcentagem de mortalidade e, posteriormente, para cálculo da taxa de viabilidade (100\% menos a porcentagem de mortalidade).

Aos 21 dias de idade, foram amostradas aleatoriamente e abatidas 24 aves, uma de cada unidade experimental, totalizando 6 aves por tratamento. Para as análises estatísticas, cada ave abatida foi considerada uma repetição para cada um dos tratamentos. Essas aves foram utilizadas para determinação da composição de carcaça; cada carcaça eviscerada foi moída e homogeneizada e para retirada de amostras, que foram conservadas a $-12{ }^{\circ} \mathrm{C}$.

Em razão da alta concentração de água e gordura na carcaça dos animais, as amostras foram submetidas inicialmente à pré-secagem em estufa com ventilação forçada a $60{ }^{\circ} \mathrm{C}$, por 96 horas, seguida de pré-desengorduramento pelo método a quente, por 4 horas, em extrator tipo Soxhlet. As amostras pré-secas e pré-desengorduradas foram, então, moídas e acondicionadas em potes de plástico para análises posteriores. As análises de matéria seca, proteína bruta e extrato etéreo das amostras foram realizadas de acordo com Silva (1990).

As análises estatísticas dos dados foram realizadas utilizando o programa SAEG (Sistema para Análises Estatísticas, versão 9.1). Os efeitos dos níveis de proteína bruta nas rações sobre o desempenho e as características 
Tabela 1 - Composição alimentar e nutricional calculada das rações experimentais para frangos de corte no período de 1 a 21 dias de idade

\begin{tabular}{|c|c|c|c|c|}
\hline \multirow[b]{2}{*}{ Ingrediente (g) } & \multicolumn{4}{|c|}{ Nível de proteína da dieta (g/kg) } \\
\hline & 230,00 & 210,00 & 190,00 & 170,00 \\
\hline Milho & 519,1 & 519,1 & 519,1 & 519,1 \\
\hline Farelo de soja & 408,1 & 355,3 & 302,6 & 249,4 \\
\hline Óleo de soja & 32,90 & 32,90 & 32,90 & 32,90 \\
\hline Amido & - & 27,40 & 54,90 & 82,20 \\
\hline Casca de soja & - & 8,68 & 17,30 & 26,10 \\
\hline Calcário & 9,85 & 8,86 & 8,76 & 8,66 \\
\hline Fosfato bicálcico & 18,60 & 19,14 & 19,60 & 20,10 \\
\hline Sal comum & 5,07 & 5,10 & 5,10 & 5,10 \\
\hline Inerte & - & 13,15 & 23,90 & 31,80 \\
\hline Premix vitamínico mineral ${ }^{1}$ & 4,00 & 4,00 & 4,00 & 4,00 \\
\hline DL-metionina & 2,40 & 2,98 & 3,60 & 4,10 \\
\hline L-lisina & 0,78 & 2,45 & 4,10 & 5,81 \\
\hline L-treonina & - & 0,83 & 1,67 & 2,52 \\
\hline L-arginina & - & - & 1,00 & 2,78 \\
\hline L-isoleucina & - & - & 0,40 & 1,40 \\
\hline L-valina & - & - & 1,00 & 2,02 \\
\hline L-fenilalanina & - & - & - & 1,45 \\
\hline L-histidina & - & - & - & 0,24 \\
\hline L-triptofano & - & - & - & 0,18 \\
\hline \multicolumn{5}{|l|}{ Composição nutricional calculada } \\
\hline Proteína bruta (g/kg) & 230,00 & 210,00 & 190,00 & 170,00 \\
\hline Energia metabolizável aparente (kcal/kg) & 2,980 & 2,980 & 2,980 & 2,980 \\
\hline Cálcio (g/kg) & 9,2 & 9,2 & 9,2 & 9,2 \\
\hline Fósforo disponível (g/kg) & 4,6 & 4,6 & 4,6 & 4,6 \\
\hline Fibra bruta (g/kg) & 31 & 31 & 31 & 31 \\
\hline Lisina digestível (g/kg) & 12,1 & 12,1 & 12,1 & 12,1 \\
\hline Metionina + cistina digestível $(\mathrm{g} / \mathrm{kg})$ & 8,6 & 8,6 & 8,6 & 8,6 \\
\hline Treonina digestível (g/kg) & 7,8 & 7,8 & 7,8 & 7,8 \\
\hline Triptofano digestível (g/kg) & 2,6 & 2,3 & 2,0 & 1,9 \\
\hline Isoleucina digestível (g/kg) & 9,2 & 8,2 & 7,6 & 7,6 \\
\hline Valina digestível (g/kg) & 9,7 & 8,7 & 8,7 & 8,7 \\
\hline Arginina digestível (g/kg) & 14,9 & 13,3 & 12,6 & 12,6 \\
\hline Fenilanina + tirosina digestível $(\mathrm{g} / \mathrm{kg})$ & 17,9 & 16,1 & 14,2 & 13,8 \\
\hline Glicina + serina total (g/kg) & 21,0 & 18,9 & 16,8 & 14,7 \\
\hline
\end{tabular}

${ }^{1}$ Suplemento vitamínico-mineral expresso por kg de ração: vitamina A - 1.333 .000 UI; vitamina $\mathrm{D}_{3}$ - 166.700 UI; vitamina E - 1.667 UI; ácido fólico - 36 mg, ácido pantotênico - $2.837 \mathrm{mg}$; ácido nicotínico - $4.000 \mathrm{mg}$; biotina - 3,34 mg; vitamina $\mathrm{B}_{6}$ (piridoxina) - 60 mg; vitamina $\mathrm{B}_{2}$ (riboflavina) - 459 mg; vitamina $\mathrm{B}_{1}$ (tiamina), 80 mg; vitamina $B_{12}-3.333$ mcg; vitamina C - 8.225 mg; vitamina $\mathrm{K}_{3}$ - 353 mg; ferro - 20.070 mg; cobre - 1.904 mg; manganês - 3.700 mg; zinco - 16.464 mg; iodo 85 mg; selênio - 24 mg; colina - 21,67 g; antioxidante - 25 g; bacitracina de zinco - 12,50 g; virginiamicina - 3,33 g; veículo QSP - 1.000 g. (6 kg/t).

de carcaça foram calculados pelo modelo de regressão, levando-se em consideração o nível de significância, o coeficiente de determinação $\left(\mathrm{r}^{2}\right)$ e a resposta biológica dos animais aos tratamentos experimentais. Os graus de liberdade dos fatores foram desdobrados em seus componentes lineares e quadráticos para a escolha do modelo de regressão que melhor descreveu as observações.

\section{Resultados e Discussão}

O desempenho das aves piorou com a redução proteica das rações, portanto, a suplementação de aminoácidos essenciais para atender às exigências preconizadas por Rostagno et al. (2005) não permitiu desempenho semelhante ao obtido com a dieta de maior nível de proteína bruta (Tabela 2). Houve efeito linear nas variáveis de desempenho e os melhores resultados de conversão alimentar, ganho de peso e peso final foram obtidos com o nível de 230,0 g/kg de PB.

Dietas com níveis mais altos de PB possivelmente atendem melhor às exigências de determinados aminoácidos não atendidas com dietas com níveis mais baixos de PB. O desempenho inferior de aves alimentadas com dietas de baixa proteína pode estar relacionado ao fornecimento inadequado de nitrogênio para síntese dos aminoácidos não-essenciais, ou o suprimento dos aminoácidos essenciais é insuficiente para a síntese proteica.

O consumo de ração sofreu efeito linear decrescente. A diminuição linear do consumo das aves neste experimento pode estar relacionada a um possível atraso no crescimento dessas aves, devido a alguma deficiência nutricional da dieta contendo baixo teor de PB. As aves, sendo menores e ainda sem capacidade de aumentar o consumo para suprir as deficiências da dieta, acabaram consumindo menos ração. 
Tabela 2 - Desempenho de frangos de corte recebendo dietas com níveis reduzidos de proteína bruta no período de 1 a 21 dias de idade

\begin{tabular}{|c|c|c|c|c|}
\hline \multirow[t]{2}{*}{ Nível de PB (g/kg) } & \multicolumn{4}{|c|}{ Variável } \\
\hline & Peso final $(\mathrm{kg})$ & Ganho peso $(\mathrm{kg})$ & Consumo de ração $(\mathrm{kg})$ & Conversão alimentar \\
\hline 230,0 & 0,9788 & 0,9381 & 1,2809 & 1,3655 \\
\hline 190,0 & 0,9135 & 0,8726 & 1,2645 & 1,4493 \\
\hline 170,0 & 0,8741 & 0,8334 & 1,2382 & 1,4862 \\
\hline CV (\%) & 2,069 & 2,151 & 1,860 & 0,970 \\
\hline Peso final & \multicolumn{4}{|c|}{ Efeito linear negativo $(\mathrm{P} \leq 0,01) \mathrm{Y}=0,580963+0,00173608 \mathrm{X}\left(\mathrm{R}^{2}=0,99\right)$} \\
\hline Ganho peso & \multicolumn{4}{|c|}{ Efeito linear negativo $(\mathrm{P} \leq 0,01) \mathrm{Y}=0,540380+0,0017349 \mathrm{X}\left(\mathrm{R}^{2}=0,99\right)$} \\
\hline Consumo & \multicolumn{4}{|c|}{ Efeito linear negativo $(\mathrm{P} \leq 0,01) \mathrm{Y}=1,13413+0,000639201 \mathrm{X}\left(\mathrm{R}^{2}=0,87\right)$} \\
\hline Conversão alimentar & \multicolumn{4}{|c|}{ Efeito linear positivo $(\mathrm{P} \leq 0,01) \mathrm{Y}=1,83933-0,00207515 \mathrm{X}\left(\mathrm{R}^{2}=0,99\right)$} \\
\hline
\end{tabular}

Resultado semelhante foi encontrado por Jiang et al. (2005), que também observaram diminuição no consumo com a redução dos níveis de PB. Por outro lado, resultados de vários trabalhos comprovam que a redução do teor de $\mathrm{PB}$ não afeta o consumo de ração (Fergunson et al., 1998; Blair et al., 1999; Bregendahl et al., 2002; Sabino et al., 2004; Faria Filho et al., 2005; Oliveira et al., 2010). De maneira contraditória, Costa et al. (2001) verificaram aumento linear do consumo com a redução do teor de PB da dieta.

Os resultados de ganho de peso e conversão alimentar estão de acordo com vários relatos da literatura de que a redução proteica em dietas para frangos de corte na fase inicial leva a perdas de desempenho (Fergunson et al., 1998; Costa et al., 2001; Hussein et al., 2001; Bregendahl et al., 2002; Si etal., 2004a,b). Jiang et al. (2005) também verificaram diminuição no ganho de peso e prejuízo na conversão alimentar de frangos de corte de 1 a 21 dias de idade alimentados com dietas com níveis mais baixos de PB. Esses autores utilizaram os níveis de 160, 180, 200, 220 e 240 g/kg de PB. Da mesma forma, Rostagno et al. (2002), trabalhando com pintos de corte de 8 a 21 dias, observaram prejuízo na conversão alimentar e no ganho de peso de aves que receberam dietas com níveis mais baixos de $\mathrm{PB}$.

Perdas no desempenho de frangos de corte na fase inicial também foram relatadas por Araújo et al. (2004), que verificaram redução no ganho de peso e prejuízo na conversão alimentar quando reduziram o nível de proteína de 220 para $180 \mathrm{~g} / \mathrm{kg}$ em dietas para frangos até 21 dias de idade. Bregendahl et al. (2002) relataram que as aves alimentadas com dietas de baixa proteína cresceram mais devagar e tiveram a eficiência alimentar alterada de forma negativa. Faria Filho et al. (2005) também relataram ganho de peso reduzido de aves alimentadas com dietas com baixos níveis proteicos. Por outro lado, Silva et al. (2006) concluíram que é possível reduzir o nível de PB da dieta inicial até 170 g/kg sem afetar o desempenho das aves desde que a dieta seja suplementada com aminoácidos essenciais e fitase.

Neste trabalho os resultados foram semelhantes aos obtidos por Rocha et al 2003, que trabalharam com dietas contendo níveis de 200, 230 e $260 \mathrm{~g} / \mathrm{kg}$ para aves de 7 a 21 dias e observaram melhores resultados para conversão alimentar das aves alimentadas com dietas com níveis de PB mais altos. Também Gonzáles-Esquerra \& Leeson (2005), trabalhando com aves de 21 a 42 dias de idade e dietas com níveis de PB de 180, 200, 230 e 260 g/kg, verificaram que o maior nível de proteína promoveu melhores ganhos de peso e conversão alimentar.

Kamran et al. (2008) também observaram redução linear no ganho de peso e prejuízo na conversão alimentar de frangos de corte com a redução dos níveis de PB em todas as fases de criação, onde avaliaram os níveis de 230, 220, 210 e $200 \mathrm{~g} / \mathrm{kg}$ para a fase de 1 a 10 dias, níveis de 220, 210 e 200 g/kg de PB dos 11 aos 26 dias e 200, 190 e 180g/kg de $\mathrm{PB}$ na idade de 27 a 35 dias.

Por outro lado, alguns estudos demonstram resultados semelhantes aos obtidos com dietas de nível alto e baixo de PB. Rostagno et al. (2002) avaliaram os efeitos da redução do conteúdo de proteína dietética sobre a produtividade de frangos de corte e verificaram que mediante a formulação de dietas com menor conteúdo de proteína, usando a proteína ideal, é possível a obtenção de desempenho similar das aves alimentadas com dietas contendo altos níveis proteicos. Ferguson et al. (1998) observaram prejuízo na conversão alimentar mas o ganho de peso não foi afetado pela redução proteica.

Não houve efeito dos níveis de PB sobre a mortalidade das aves (Tabela 3). Houve efeito linear dos tratamentos sobre o conteúdo de matéria seca e extrato etéreo da carcaça (Tabela 4) e isso confirma que os níveis mais baixos de PB apresentaram maior teor de MS e gordura. Também não 
Tabela 3 - Viabilidade de aves no período de 1 a 21 dias de idade recebendo rações com diferentes níveis proteicos

\begin{tabular}{ccc}
\hline Nível de PB $(\mathrm{g} / \mathrm{kg})$ & Viabilidade (\%) & CV (\%) \\
\hline 230,0 & 97,61 & 2,96 \\
210,0 & 97,62 & 98,09 \\
190,0 & 96,16 & $\mathrm{~ns}$ \\
170,0 & significância & \\
\hline
\end{tabular}

ns - efeito não-significativo; PB - proteína bruta; CV - coeficiente de variação.

Tabela 4 - Composição percentual de carcaça de frangos de corte aos 21 dias de idade recebendo dietas com diferentes níveis de proteína bruta

\begin{tabular}{ccccc}
\hline Nível de PB $(\mathrm{g} / \mathrm{kg})$ & Matéria seca $(\mathrm{g} / 100 \mathrm{~g})$ & Proteína bruta $(\mathrm{g} / 100 \mathrm{~g})$ & Extrato etéreo $(\mathrm{g} / 100 \mathrm{~g})$ & Matéria mineral $(\mathrm{g} / 100 \mathrm{~g})$ \\
\hline 230,0 & 29,63 & 16,92 & 9,47 & 2,45 \\
210,0 & 30,16 & 16,44 & 10,19 & 2,77 \\
190,0 & 32,09 & 16,72 & 12,63 & 2,77 \\
170,0 & 31,80 & 16,63 & 12,16 & 2,75 \\
CV (\%) & 3,15 & 4,79 & 10,54 & 9,78 \\
Significância & $\mathrm{P}<0,01$ & $\mathrm{P}>0,05$ & $\mathrm{P}<0,01$ & $\mathrm{P}>0,05$
\end{tabular}

Equações de regressão

Matéria seca $\quad$ Efeito linear positivo $(\mathrm{P}<0,01) \hat{\mathrm{Y}}=39,3941-0,0423531 \mathrm{x}\left(\mathrm{R}^{2}=0,81\right)$

Extrato etéreo $\quad$ Efeito linear positivo $(\mathrm{P}<0,01) \hat{\mathrm{Y}}=21,6337-0,0525934 \mathrm{x}\left(\mathrm{R}^{2}=0,80\right)$

$\mathrm{P}<0,01$ - Significativo estatisticamente a $1 \%$ de probabilidade; $\mathrm{P}>0,05$ - efeito não-significativo.

houve efeito dos níveis de PB sobre o teor de PB e matéria mineral na carcaça.

Teores semelhantes de proteína na carcaça de aves aos 21 dias de idade que receberam dietas com reduzidos níveis de proteína também foram encontrados por Bregendahl et al. (2002). Aumento dos níveis de gordura na carcaça com redução dos teores de PB da dieta tem sido observado com frequência nos trabalhos científicos (Costa et al., 2001; Bregendahl et al., 2002; Silva et al., 2003). De acordo com Kerr et al. (1995) e Tuitoek et al. (1997), as carcaças ficam mais gordas quando os animais são alimentados com dietas pobres em proteína bruta suplementadas com aminoácidos. Isso se deve ao fato de haver economia de energia quando não se tem excesso de nitrogênio para ser eliminado.

Com isso, compreende-se o aumento dos teores de extrato etéreo nas carcaças dos frangos que receberam dietas pobres em PB. Existe sobra de energia que está sendo estocada na forma de gordura. Segundo Lesson \& Summers (2001), excessos de energia não podem ser excretados pelo corpo do animal e consequentemente são estocados como gordura.

Como os teores de matéria mineral e proteína bruta não foram influenciados pelos tratamentos, conclui-se que o aumento do teor de matéria seca está diretamente relacionado ao aumento de gordura na carcaça.

\section{Conclusões}

A redução da proteína bruta das dietas diminui o desempenho das aves e aumenta a deposição de gordura na carcaça de frangos de corte machos de 1 a 21 dias de idade, no entanto a redução proteica não afeta a viabilidade da exploração avícola até o período estudado.

\section{Referências}

ARAÚJO, L.F.; JUNQUEIRA, O.M.; ARAÚJO, C.S.S. Redução do nível protéico da dieta, através da formulação baseada em aminoácidos digestíveis. Ciência Rural, v.34, p.1197-1201, 2004.

BLAIR, R.; JACOB, J.P.; IBRAHIM, S. et al. A quantitative assessment of reduced protein diets and supplements to improve nitrogen utilization. Journal Applied Poultry Research, v.8, p.25-47, 1999 .

BREGENDAHL, K.; SELL, J.L.; ZIMMERMAN, DR. Effect of low-protein diets on growth performance and body composition of broiler chicks. Poultry Science, v.81, p.1156-1167, 2002.

COSTA, F.G.P.; ROSTAGNO, H.S.; ALBINO, L.F.T. et al. Níveis dietéticos de proteína bruta para frangos de corte de 1 a 21 e 22 a 42 dias de idade. Revista Brasileira de Zootecnia, v.30, p.1498-1505, 2001.

FARIA FILHO, D.E.; ROSA, P.S.; VIEIRA, B.S. et al. Protein levels and environmental temperature effects on carcass characteristics, performance, and nitrogen excretion of broiler chickens from 7 to 21 days of age. Revista Brasileira de Ciência Avícola, v.7, p.247-253, 2005.

FERGUSON, N.S.; GATES, R.S.; TARABA, J.L. et al. The effect of dietary protein and phosphorus on ammonia concentration and litter composition in broilers. Poultry Science, v.77, p.1085-1093, 1998.

GONZALEZ-ESQUERRA, R.; LEESON, S. Effects of acute versus chronic heat stress on broiler response to dietary protein. Poultry Science, v.84, p.1562-1569, 2005.

HUSSEIN, A.S.; CANTOR, A.H.; PESCATORE, A.J. Effect of low protein diets with amino acid supplementation on broiler growth. Journal of Applied Poultry Research, v.10, p.354-362, 2001.

JIANG, Q.; WALDROUP, P.W.; FRITTS, C.A. Improving the utilization of diets in crude protein for broiler chicken. 1. Evaluation of special amino acid supplementation to diets low in crude protein. International Journal of Poultry Science, v.4, n.3, p.115-122, 2005. 
KAMRAN, Z.; SARWAR,M.; NISA, M. et al. Effect of low-protein diets having constant energy-to-protein ratio on performance and carcass characteristics of broiler chickens from one to thirtyfive days of age. Poultry Science, v.87, p.468-474, 2008.

KERR, B.J.; McKEITH, F.K.; EASTER, R.A. Effect of performance and carcass characteristics of nursery to finisher pigs fed reduced crude protein, amino acid-supplemented diets. Journal of Animal Science, v.73, p.433-440, 1995.

LEESON, S.; SUMMERS, J.D. Nutrition of the chicken. 4.ed. Ontario: University Books, 2001. 413p.

OLIVEIRA, W.P.; OLIVEIRA, R.F.M.; DONZELE, J.L. et al. Redução do nível de proteína bruta em rações para frangos de corte em ambientes de estresse por calor. Revista Brasileira de Zootecnia, v.39, p.1092-1098, 2010.

ROCHA, P.T.; STRINGHINI, J.H.; ANDRADE, M.A. et al. Desempenho de frangos de corte alimentados com rações pré-iniciais contendo diferentes níveis de proteína bruta e energia metabolizável. Revista Brasileira de Zootecnia, v.32, p.162-170, 2003.

ROSTAGNO, H.S.; VARGAS JUNIOR, J.G.; ALBINO, L.F.T. et al. Níveis de proteína e aminoácidos em rações de pinto de corte. Revista Brasileira de Ciência Avícola, v.4, p.49, 2002. (supl.)

ROSTAGNO, H.S.; ALBINO, L.F.T.; DONZELE, J.L. et al. Tabelas brasileiras para aves e suínos: composição de alimentos e exigências nutricionais. 2.ed. Viçosa, MG: UFV, 2005. 186p.

SABINO, H.F.N.; SAKOMURA, N.K.; NEME, R. et al. Níveis protéicos na ração de frangos de corte na fase de crescimento. Pesquisa Agropecuária Brasileira, v.39, p.407-412, 2004.
SI, J.; FRITTS, C.A.; WALDROUP, P.W. et al. Effects of excess methionine from meeting needs for total sulfur amino acids on utilization of diets low in crude protein by broiler chicks. Journal Applied Poultry Research, v.13, p.579-587, 2004 a.

SI, J.; FRITTS, C.A.; WALDROUP, P.W. et al. Effects of tryptophan to large neutral amino acid ratios and overall amino acid levels on utilization of diets low in crude protein by broilers. Journal Applied Poultry Research, v.13, p.570-578, 2004b.

SILVA, D.J. Análise de alimentos: métodos químicos e biológicos. 2.ed. Viçosa, MG: UFV, 1990. 166p.

SILVA, J.H.V.; ALBINO, L.F.T.; NASCIMENTO, A.H. Estimativas da composição anatômica da carcaça de frangos de corte com base no nível de proteína da ração e peso da carcaça. Revista Brasileira de Zootecnia, v.32, p.344-352, 2003.

SILVA, Y.L.; RODRIGUES, P.B.; FREITAS, R.T.F. et al. Redução de proteína e fósforo em rações com fitase para frangos de corte no período de 1 a 21 dias de idade. Desempenho e teores de minerais na cama. Revista Brasileira de Zootecnia, v.35, p.840-848, 2006.

SKALAN, D.; PLAVNIK, I. Interactions between dietary crude protein and essencial amino acid intake on performance in broilers. British Poultry Science, v.43, p.442-449, 2002.

TUITOEK, K.; YOUNG, L.G.; LANGE, C.F.M. et al. The effect of reducing excess dietary amino acids on growing-finishing pig performance: An evaluation of the ideal protein concept. Journal of Animal Science, v.75, p.1575-1583, 1997. 